This item was submitted to Loughborough's Research Repository by the author.

Items in Figshare are protected by copyright, with all rights reserved, unless otherwise indicated.

\title{
Cities at risk? Exploring the synergies between smartphones and everyday vulnerabilities
}

\section{PLEASE CITE THE PUBLISHED VERSION}

https://doi.org/10.1016/j.cities.2018.06.015

\section{PUBLISHER}

(C) Elsevier

\section{VERSION}

AM (Accepted Manuscript)

\section{PUBLISHER STATEMENT}

This paper was accepted for publication in the journal Cities and the definitive published version is available at https://doi.org/10.1016/j.cities.2018.06.015.

\section{LICENCE}

CC BY-NC-ND 4.0

\section{REPOSITORY RECORD}

Amankwaa, Ebenezer F., and Karen Blay. 2019. "Cities at Risk? Exploring the Synergies Between Smartphones and Everyday Vulnerabilities". figshare. https://hdl.handle.net/2134/34070. 


\title{
Cities at risk? Exploring the synergies between smartphones and everyday vulnerabilities
}

\author{
Ebenezer F. Amankwaa ${ }^{1}$, Karen B. Blay ${ }^{2}$
}

1 Department of Geography and Resource Development, University of Ghana, Ghana

2 School of Architecture, Building and Civil Engineering, Loughborough University, UK

\begin{abstract}
Smartphones present new forms of spatiality and sociality for cities worldwide. The sudden outburst in smartphone technologies has revolutionised human relations creating new possibilities of encounter and connectivity. This paper examines people's smartphone usage patterns and highlights how this is increasing human vulnerabilities in cities with resultant wider societal implications. Drawing on the theory of vulnerability, Hofstede's cultural dimension theory and carrying out semi-structured interviews in the United Kingdom and Ghana, the paper reveals that the current scale of usage and addiction to smartphones and social media are fostering emerging forms of everyday vulnerabilities. Victimisation, privacy breach, home emergencies and road accidents are prevalent vulnerabilities in both Accra and London. By comparing participants' smartphone usage patterns and their motives for adopting or ignoring certain social media practices, the study illustrates how the concept of attitudinal vulnerability extends our understanding of Hofstede's theory of collectivism and individualism. While the finding from Accra complicates Hofstede's collectivism label as there seems to be a loss of genuine sense of care and people-centeredness among participants it confirms individualism tendencies among the participants in London though some tendencies of 'virtual collectivism' were observed. In conclusion, the study emphasises how significant behavioural changes among smartphone users can reduce human-induced vulnerabilities in cities. By so doing, we add weight to the literature that focuses on the importance of developing context-specific cutting- edge ICT policies vis-à-vis building smart, safe and sustainable cities.
\end{abstract}

Keywords: Smartphones, Social media networks Vulnerabilities Individualism Collectivism Smart city

\section{Introduction}

As the information and communication technologies (ICTs) pervade into our everyday lives, so have mobile phones become smarter in providing connectivity to the world around us. The scale of human connectivity has reached unprecedented levels such that smartphones are just like personal computers and most people now use one or more online social media services including WhatsApp, Facebook, Twitter, YouTube, Instagram and Snapchat for watching videos, expressing themselves and searching and sharing information. Worldwide, smartphones were used by 1.85 billion people in 2014 . This number reached

\footnotetext{
1 Corresponding author at: P.O. Box Lg 59, Legon, Accra, Ghana.

E-mail addresses: efamankwaa@st.ug.edu.gh (E.F. Amankwaa), k.b.blay@lboro.ac.uk (K.B. Blay).
} 
2.32 billion in 2017 and is expected to reach 2.87 billion in 2020 (Statista, 2017). The fast pace of technological innovation and penetration is rapidly changing the face of our cities into what are now referred to as "smart-cities" - whereby urban locales integrate cyber- physical technologies and infrastructure to create environmental and economic efficiency while improving the overall quality of life (Neirotti, De Marco, Cagliano, Mangano, \& Scorrano, 2014; OCIA, 2015). While smart-city technologies enhance virtual mobility and promote smarter infrastructures that reduce hazards (see for example Aina, 2017 on GeolCT; Hampshire et al., 2015 on m-health), they are also associated with issues of cyber-crimes and human-induced risks (Alsaleh, Alomar, \& Alarifi, 2017). The diffusion of ICT and smart mobile phones (SMPs) in today's 'virtual cities' presents a host of opportunities (efficiencies and convenience) and vulnerabilities (privacy threats and loss of personal care) (see for instance Aina, 2017; Battarra, Gargiulo, Pappalardo, Boiano, \& Oliva, 2016). In this paper, we define SMPs as multifunctional devices which are used for networking, sharing information and promoting fame, with the potential of shrinking genuine human care and societal cohesiveness.

A growing scholarship shows how SMPs are reshaping cities and presenting new forms of spatiality and sociality, particularly in relation to a more mobile life, and the way business is done, social network is built, and romantic courtship is forged and nurtured (Buglass, Binder, Betts, \& Underwood, 2016; Chan, 2015). For instance, Turkle (2011) draws our attention to the rising digital dependency in the global North, linking the intensive use of mobile technologies with a decline in genuine face-to-face human connections. Pain et al. (2005) highlight the different ways that young people and their parents in the UK use smartphones in managing and negotiating safety, raising questions as to whether phones are technologies of surveillance or empowerment. In the global South (e.g. Ghana, Malawi and South Africa), Porter et al. (2015) have documented the intergenerational differences in people's phone usage emphasising how the youth mostly are repositioning themselves as family information hubs with extensive phone use duration. While these previous studies are unique in terms of focus and contribution to scholarship, not much attention has been given to the contribution of smartphones to risk accumulation in cities. This makes researching into smartphone users' practices and the dynamics of everyday risks imperative.

This paper interrogates these shifting usage patterns of SMPs and the new virtual opportunities and associated vulnerabilities SMPs create, with particular emphasis on the synergies and implications of addiction, distraction, emergencies and response. Specifically, the paper illustrates how SMPS contribute to human-induced risks such as home emergencies, distracted walking and driving accidents, and fatalities, as well as how SMPs influence people's response to such risks; that is, either posting real time information or providing an intervention. The paper argues that the use of smartphones is creating new forms of attitudinal vulnerabilities in cities which have resultant wider implications for Hofstede's theory on collectivism and individualism. These dynamics are posing emerging challenges for city governments in relation to the achievement of the urban Sustainable Development Goal (SDG) since SMPs which are meant to improve efficiency and inclusivity are also bedevilled with issues of exclusion and everyday risks. This paper addresses two key questions: How are smartphones shaping cities in terms of people's usage patterns and experience of attitudinal vulnerabilities like privacy threats, home emergencies and road accidents? How are people's SMP usage and emergency responses altering the notions of societal cohesiveness and cultural identity? By answering these questions, city planners, police service and security analysts would be able to 
identify and focus on the factors that influence smartphones users' practices, behavioural changes and attitudinal vulnerabilities and incorporate such thinking into smart city design thereby promoting continued people-oriented protection strategies in relation to this evolving technology. Also, examining these issues would contribute to studies highlighting the opportunities and vulnerabilities associated with SMPs (Alsaleh et al., 2017; Buglass et al., 2016; Mahmood, 2013). Ultimately, the study would add to the debates on smart cities and digital technologies in terms of the need for increasing awareness on security and privacy threats especially with regards to the 'ICT systems', 'economy' and 'people' domains of smart cities (see Neirotti et al., 2014). This will eventually aid policy makers and researchers to develop tailor-made mechanisms that minimize human-induced SMP related risks. The case studies to illustrate these intersections are Ghana (representing global South) and the UK (representing global North).

This paper is organized as follows: first, the concept of vulnerability and how smartphone technologies could be used to understand emerging forms of human vulnerabilities are discussed. Afterwards, the issues of SMP usage patterns, human vulnerabilities, cultural identity and ICT policy are stitched together to provide a conceptual lens for the study. This is followed by a brief profile of the case study cities and discussion of the methodology employed to collect data. Subsequently, results from the case studies are discussed under three themes: SMP usage patterns; human vulnerabilities and emergency response; and societal cohesiveness and cultural identity; in accordance with the conceptual framework. The final sections revisit the conceptual framework and provide some conclusions and recommendations on how SMPs can be leveraged to reduce vulnerabilities, raise awareness and strengthen societal cohesiveness.

\section{Conceptualizing human vulnerabilities and smart mobile phones (SMPs) in cities}

Vulnerability can be defined as the susceptibility to harm, a potential change when struck with disruption and the absence of adaptation (Adger, 2006; Gallopín, 2006). Vulnerability is influenced by exposure and sensitivity. While exposure shows the extent to which an entity is subject to a disruption (Gallopín, 2006), often characterised by duration, proximity or level of subjectivity (Smit \& Wandel, 2006); sensitivity is the inherent property of the entity which exists prior to a disruption and has its magnitude dependent on the extent of exposure to the disruption (Gallopín, 2006). When exposed to disruptions, sensitivity of the entity utilizes its adaptive capacity to modify the circumstance to reduce vulnerability (Birkmann et al., 2013). Thus, adaptive capacity enables the entity to cope with, persist or be flexible towards the disruptions and thus, reduce vulnerability. The sources of disruptions which lead to vulnerability vary; examples are natural hazards and human-induced risks. Both sources lead to varying vulnerabilities such as economic, social and cultural (Birkmann et al., 2013). In the past few decades, discussions about natural hazards have received significant attention which has brought to the limelight issues of flood reduction (Schanze, 2006) and climate change adaptation (Adger, 2006). Human-induced risks, on the other hand, have not received commensurate academic attention largely due to the lack of appreciation of its multi-dimensionality and pathways to impact. However, as argued in this paper, human-induced risks present everyday vulnerabilities which are taken for granted and often go underreported.

Human vulnerability refers to the susceptibility to harm caused by human activities (i.e. induced risks). 
These activities are the common sources of disruptions in cities (Birkmann et al., 2013; Cannon, Twigg, \& Rowell, 2003) with tangible manifestations in everyday life. The growing technological drive in cities has compounded the already existing induced risks. Human-induced risk has a direct relationship with the level of addiction to technological tools especially smart mobile phones (SMPs). According to King et al. (2013) there is severe anxiety and discomfort among people when they are unable to access their SMPs. This situation is termed as nomophobia (King et al., 2013). The increasing level of addiction to SMPs has influenced and is being influenced by attitudinal vulnerabilities. Attitudinal vulnerability refers to the susceptibility to harm due to addiction or dependency on external support (Bartlett, Brown, Shattell, Wright, \& Lewallen, 2013; Cannon et al., 2003). Addiction is defined to mean the compulsive aspects of behaviour, the presence of physical dependence and diminished control (Walters \& Gilbert, 2000). Employing this definition in the SMP context, the addiction of people to SMP can be said to introduce attitudinal vulnerabilities which influence people's response to SMP related emergencies.

Smartphone addiction is considered as the inability to control smartphone use despite negative effects on users. Smartphone addiction is regarded to be rooted in internet addiction due to the similarity of the symptoms and negative effects on users. The addiction bar for internet services is estimated at $3 \mathrm{~h}$ (Bi et al., 2015; Cha \& Se0, 2018; Egger \& Rauterberg, 1996). The average smartphone user checks their device 85 times a day, for a mean duration of $10-250 \mathrm{~s}$, and use up to 1-1000 megabyte (MB) data per day (Falaki, Mahajan, \& Kandula, 2010). Smartphone addiction could be categorized as a behavioural addiction, such as internet addiction which is an impulse control disorder characterised by pathological internet use (see Cha \& Se0, 2018). SMPs are not only addictive and pervasive but also, distracting, and subtly contribute to and create new forms of everyday vulnerabilities. For instance, the use of online social media platforms like WhatsApp, Facebook, Twitter, YouTube, Instagram and Snapchat are characterised by the addiction to seek and share information; and the fame associated with the process which is usually measured by the number of posts, likes, comments and shares the poster or blogger attracts. The orientation towards public fame motivates SMP users to quickly share information and upload events on social media and be tagged as 'first- timers' (see Greenwood, 2013; Heimbach, Schiller, Strufe, \& Hinz, 2015). This addiction and crave for fame have been associated with several challenges. For instance, the use of SMP technologies while driving is identified in the United Kingdom as a major cause of road fatalities (Ingham, 2014; McCann, 2016). The situation is not different from Ghana where the use of mobile phones while driving has been reported as the second major cause of road accidents (GhanaWeb, 2013). Meanwhile, this multi-dimensional aspect of SMP related risks and emergencies, particularly at the individual and household levels are poorly understood by relevant stakeholders, personally handled by users and victims and often not accounted for by city authorities.

In addition, there is a worrying trend in emergency response practices whereby people are increasingly becoming less judgmental of situations and more oriented towards information sharing, thus recording events and sharing them on social media, than providing an intervention to save the situation (Fuchs, 2017). While this switch in orientation promotes real-time information sharing that can create awareness and trigger investigations, it also perpetuates attitudinal vulnerabilities by putting SMP users and non-users' lives and properties at risk. According to Halevi, Lewis, and Memon (2013) and Cha and Seo (2018) socio- demographic factors such as gender, education, personal experiences and personal traits largely influence human vulnerabilities and people's responses orientation. For instance, males and females have different SMP use patterns as they have differing levels of involvement or 
dependency on their phones, all of which have wider implications for societal cohesiveness and cultural identity.

Drawing on the globalization literature, this paper situates the issues outlined above within Hofstede's theory of individualism and collectivism (Fiske, 2002; Parker, Haytko, \& Hermans, 2009). The individualism and collectivism constructs have been significantly useful for research since Hofstede (1980) identified them as opposite poles of a value dimension differentiating world cultures. The assumption that groups are socially bound together by a sense of community spirit and norms and that individuals are defined as part of a collective (Parker et al., 2009) seems to be the central theme of collectivism. Such emphasis on group harmony and homogeneity influences people's desire to 'blend in' rather than stand out: giving them the perceived right to get involved in the affairs of others (Triandis, 2004). In contrast, individualistic cultures place greater emphasis on individuals becoming more loosely connected to groups. Such emphasis on self-sufficiency, self-esteem, pursuit of individual happiness, and competitive relationships with other groups influence people's desire to have respect for individuality or privacy of group members (Buglass et al., 2016; Morris, Davis, \& Allene, 1994).

Research using these concepts suggests that the cultures of Africa, Asia and Latin America tend to be collectivistic; while those of Western Europe, Canada and the United States tend to be individualistic (Parker et al., 2009; Triandis, 1995). Thus, an examination of Hofstede's $(1980,1991)$ works reveals a predominance of developed nations ranking high on the individualism scale, while less developed nations rank lower. This classification has informed our choice of the UK and Ghana as case study countries to illustrate the implications of SMPs usage on cultural identities and societal cohesiveness. By highlighting these concerns our paper seeks to contribute to the global campaign and awareness creation agenda for policy makers in terms of how SMPs and online social media networks influence people's behaviour and way of life (Ruths \& Pfeffer, 2014) thereby exacerbating and introducing new forms of everyday vulnerabilities. These various insights highlighted above are drawn upon to develop a conceptual framework that shows the relationships between SMP usage patterns, human vulnerabilities, cultural identities and its influence on ICT policies. This has been illustrated in Fig. 1.

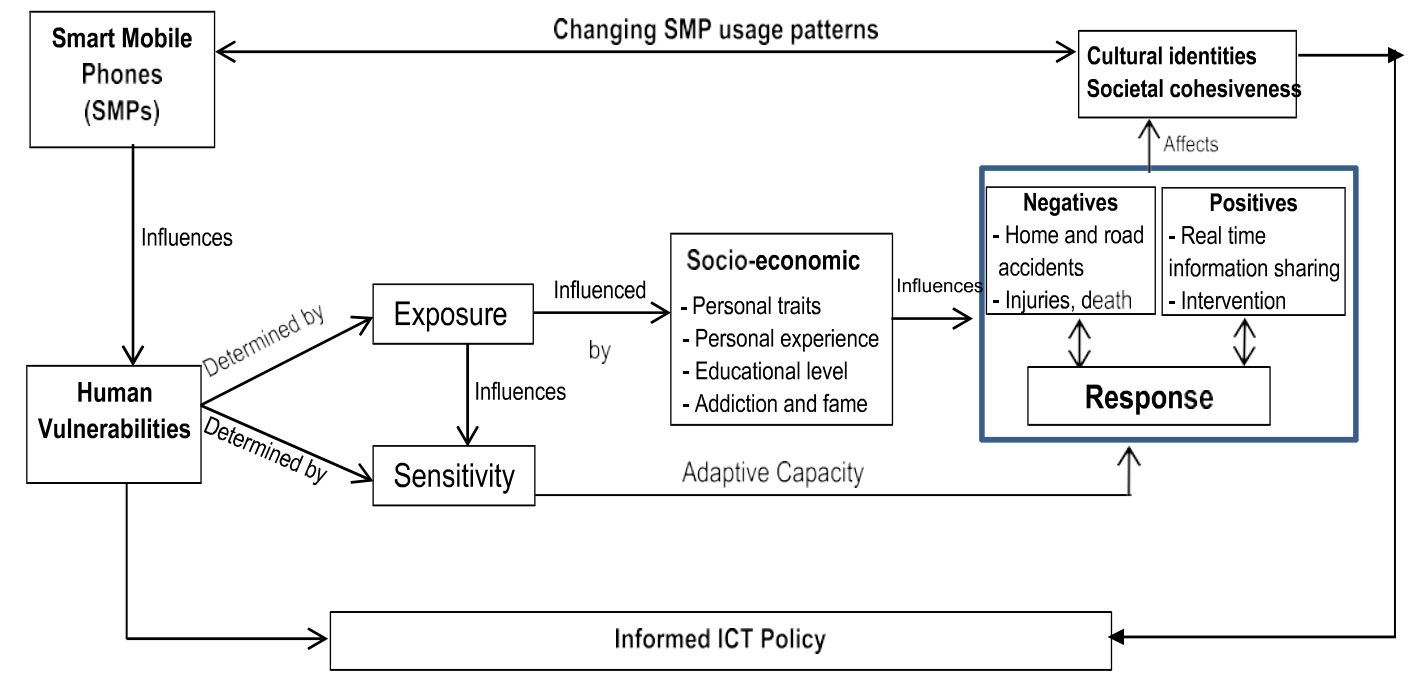

Fig. 1. Conceptual framing of SMP usage patterns, human vulnerabilities, cultural identity and 


\section{ICT policy. Source: Authors' construct, 2017.}

\section{Study area and methods}

\subsection{Study area}

The research was conducted in England and Ghana as they provided contrasting cases on SMPs and human vulnerabilities within a global context. England is a developed country which is part of the United Kingdom. It has a population of about 65 million with a high literacy level of $84 \%$ (ONS, 2016). Technology adoption is around 88\% (ONS, 2017). The capital of England, London, comprises diverse group of people with the city well known for its high technological adoption. Given London's status as a tourist attraction destination and home for international businesses (Guardian, 2014), its population has increased to about nine million in 2016. The technological drive and scale of usage within the city have made smartphones a part of people's daily lives and activities. For instance, SMPs are used in London for planning journeys (TFL, 2017), making payments (Barclays, 2017), locating friends and residences, ordering food, seeking medical help and planning what to wear for events (Chan, 2015; Ozcan, 2014). Given its individualistic culture, England has structures and support systems that promote and prioritize self-reliance. For instance, the government provides aid and social support schemes to individuals (HMRS, 2017) unlike Ghana where the collectivistic culture entreats the family systems to provide social support especially for the aged. SMPs are unconsciously eroding cultural traits and changing people's way of life. Based on its cosmopolitan and technological driven characteristics, this paper examines whether SMP technologies, associated forms of vulnerabilities and people's response are shaping London's culture; that is whether it is still firmly individualistic or if it is moving towards a more socialist, tight-fitting collectivist setting.

Ghana is a developing country located on the West coast of Africa. It is geographically the closest landmark to the center of the world. It is predominantly urban (52\%) with a total population of about 27 million. Ghana has the 4th fastest internet connection on the African continent (Akamai, 2016) and has a high taste for technology adoption. Between 2008 and 2010 the proportion of the population with internet access increased from $4.2 \%$ to $7.8 \%$, and to $17.1 \%$ in 2012 (ITU, 2013). Ghanaians, just like the rest of the world, with access to the internet has a tremendous use of real time communications through the numerous social media platforms such as WhatsApp, Facebook, Twitter, YouTube, and Snapchat. The Internet usage report released by Internet World Statistics (2017) reveals that approximately $12.9 \%$ of Ghanaians are using Facebook. Accra is the capital and largest city of Ghana with an urban population of 2.27 million (GSS, 2012). The Greater Accra Metropolitan Area (GAMA) has about four million inhabitants, which makes it the 11th largest metro area in Africa (Amankwaa, 2017). Accra is cosmopolitan with about $27.8 \%$ of the city dwellers using online social media platforms like Facebook (Internet World Statistics, 2017). Given its collectivistic culture, Ghanaians are known to prioritize group solidary and societal cohesiveness over individual goals. While this assumption may have been supported in the past, it is plausible that as Ghana experiences rapid technological adoption rate and western trends, and progresses as a lower middle-income nation, the collectivistic culture will be under environmental pressure to becoming more individualistic in nature. Therefore, using Accra as a case study, this paper examines whether the Ghanaian culture is still solidly collectivistic or if it is 
moving towards a more liberal, loose-fitting individualistic setting under the aegis of SMPs technologies, associated forms of vulnerability and response to risks.

\subsection{Methods}

A qualitative method involving semi-structured interviews was adopted to collect data for this study (Saunders, Lewis, \& Thornhill, 2012). This approach afforded us the opportunity to explore in details people's use of smartphones, changing trends, vulnerability experiences and response and pathways to influencing cultural identity. A purposive sampling technique was employed to select individuals who had knowledge and experience in smartphones usage and related vulnerabilities. This method entailed a random sampling strategy (Marshall, 1996) at the initial stages of the data collection process. Further, snowball and convenience sampling approaches were employed to gain access to more respondents. Due to the challenge in identifying respondents, snowball method was predominantly used in London and this process afforded us the opportunity to identify potential respondents through previous interviewees (Fellows \& Liu, 2008). In Accra, the convenience sampling strategy was mainly utilized due to the relatively accessible sample population. The reason for following this recruitment approaches was to obtain a sample that represented smartphone users with varying demographic backgrounds. For this reason, our sample had differing age groups and diversity in occupation, marital status and income level. The selected sample only included users who had been using smartphones for more than 3 months and excluded participants whose ages were below 18 years and above 40 years.

In all, 40 semi-structured interviews, each lasting between 30 and 60 min, were conducted with individuals who resided in Accra and London following their verbal informed consent. To achieve a representative sample, participants selection was done to cover a diversity of areas in Accra and London, thus the central and peripheral locations of these cities. The participants were aged between 18 and 40 years with the average age being 27 years. In Accra interview participants comprised 11 males and 9 females, while in London they were 8 males and 12 females, representing $52 \%$ and $48 \%$ male and female respondents respectively. The educational level of respondents varied; $58 \%$ had undergraduate degrees, $20 \%$ had postgraduate degree and $22 \%$ had secondary education. Table 1 captures details of the demographic data of respondents in Accra and London.

Table 1: Demographic overview of respondents

\begin{tabular}{|r|l|r|l|l|l|l|l|l|l|}
\hline \multicolumn{9}{|c|}{ Accra-Ghana } & \multicolumn{1}{|c|}{ London-UK } \\
\hline \multicolumn{1}{|c|}{ Interview } & Gender & \multicolumn{1}{|c|}{ Age } & Education & Location & Interview & Gender & Age & Education & Location \\
\hline $\mathbf{1}$ & Male & 32 & $\begin{array}{l}\text { University } \\
\text { degree }\end{array}$ & Agbogba & $\mathbf{1}$ & Female & 25 & $\begin{array}{l}\text { Postgraduate } \\
\text { degree }\end{array}$ & Hackney \\
\hline $\mathbf{2}$ & Male & 40 & $\begin{array}{l}\text { University } \\
\text { degree }\end{array}$ & $\begin{array}{l}\text { Dansoman } \\
\text { estate }\end{array}$ & $\mathbf{2}$ & Female & 24 & $\begin{array}{l}\text { Secondary } \\
\text { education }\end{array}$ & Islington \\
\hline $\mathbf{3}$ & Female & 25 & $\begin{array}{l}\text { University } \\
\text { degree }\end{array}$ & Mampbi & $\mathbf{3}$ & Female & 25 & $\begin{array}{l}\text { University } \\
\text { degree }\end{array}$ & Lewisham \\
\hline $\mathbf{4}$ & Male & 34 & $\begin{array}{l}\text { Secondary } \\
\text { education }\end{array}$ & Ablekuma & $\mathbf{4}$ & Male & 27 & $\begin{array}{l}\text { University } \\
\text { degree }\end{array}$ & Croydon \\
\hline $\mathbf{5}$ & Male & 25 & $\begin{array}{l}\text { Secondary } \\
\text { education }\end{array}$ & Circle & $\mathbf{5}$ & Female & 26 & $\begin{array}{l}\text { Secondary } \\
\text { education }\end{array}$ & Haringey \\
\hline $\mathbf{6}$ & Male & 34 & $\begin{array}{l}\text { University } \\
\text { degree }\end{array}$ & Teshie & $\mathbf{6}$ & Female & 24 & $\begin{array}{l}\text { University } \\
\text { degree }\end{array}$ & Edmonton \\
\hline
\end{tabular}




\begin{tabular}{|c|c|c|c|c|c|c|c|c|c|}
\hline 7 & Female & 20 & $\begin{array}{l}\text { Secondary } \\
\text { education }\end{array}$ & Pokuase & 7 & Female & 29 & $\begin{array}{l}\text { University } \\
\text { degree }\end{array}$ & Euston \\
\hline 8 & Male & 24 & $\begin{array}{l}\text { University } \\
\text { degree }\end{array}$ & Madina & 8 & Female & 27 & $\begin{array}{l}\text { University } \\
\text { degree }\end{array}$ & Hackney \\
\hline 9 & Male & 25 & $\begin{array}{l}\text { Secondary } \\
\text { education }\end{array}$ & Lapaz & 9 & Female & 18 & $\begin{array}{l}\text { University } \\
\text { degree }\end{array}$ & Victoria \\
\hline 10 & Female & 23 & $\begin{array}{l}\text { University } \\
\text { degree }\end{array}$ & Nungua & 10 & Male & 22 & $\begin{array}{l}\text { University } \\
\text { degree }\end{array}$ & Camden \\
\hline 11 & Male & 25 & $\begin{array}{l}\text { Secondary } \\
\text { education }\end{array}$ & Haatso & 11 & Male & 29 & $\begin{array}{l}\text { University } \\
\text { degree }\end{array}$ & Seven Sisters \\
\hline 12 & Female & 20 & $\begin{array}{l}\text { Secondary } \\
\text { education }\end{array}$ & Legon & 12 & Female & 25 & $\begin{array}{l}\text { Postgraduate } \\
\text { degree }\end{array}$ & Haringey \\
\hline 13 & Female & 29 & $\begin{array}{l}\text { University } \\
\text { degree }\end{array}$ & Spintex & 13 & Female & 28 & $\begin{array}{l}\text { University } \\
\text { degree }\end{array}$ & $\begin{array}{l}\text { Central } \\
\text { London }\end{array}$ \\
\hline 14 & Female & 27 & $\begin{array}{l}\text { University } \\
\text { degree }\end{array}$ & Dzorwulu & 14 & Female & 24 & $\begin{array}{l}\text { University } \\
\text { degree }\end{array}$ & Southwark \\
\hline 15 & Male & 25 & $\begin{array}{l}\text { Secondary } \\
\text { education }\end{array}$ & Tema & 15 & Male & 30 & $\begin{array}{l}\text { University } \\
\text { degree }\end{array}$ & Greenwich \\
\hline 16 & Female & 19 & $\begin{array}{l}\text { Secondary } \\
\text { education }\end{array}$ & Madina & 16 & Male & 33 & $\begin{array}{l}\text { University } \\
\text { degree }\end{array}$ & Old Kent road \\
\hline 17 & Male & 26 & $\begin{array}{l}\text { University } \\
\text { degree }\end{array}$ & Achimota & 17 & Male & 30 & $\begin{array}{l}\text { University } \\
\text { degree }\end{array}$ & Southwark \\
\hline 18 & Female & 34 & $\begin{array}{l}\text { University } \\
\text { degree }\end{array}$ & $\begin{array}{l}\text { Accra } \\
\text { Central }\end{array}$ & 18 & Male & 31 & $\begin{array}{l}\text { University } \\
\text { degree }\end{array}$ & Vauxhall \\
\hline 19 & Male & 36 & $\begin{array}{l}\text { Postgraduate } \\
\text { degree }\end{array}$ & Banana Inn & 19 & Female & 25 & $\begin{array}{l}\text { University } \\
\text { degree }\end{array}$ & Paddington \\
\hline 20 & Female & 30 & $\begin{array}{l}\text { Postgraduate } \\
\text { degree }\end{array}$ & $\begin{array}{l}\text { American } \\
\text { house }\end{array}$ & 20 & Male & 35 & $\begin{array}{l}\text { University } \\
\text { degree }\end{array}$ & Richmond \\
\hline
\end{tabular}

Interviews were carried out both in person and on phone, and the semi-structured questions we used in our interviews were grouped into four main sections namely; personal details; SMP usage patterns; vulnerability and societal cohesiveness; and positive impacts of SMPs. Questions under personal details covered age, gender, education, location and marital status, whereas those under SMP usage patterns included duration of SMP ownership/usage, main uses of SMPs, changes in usage pattern, mostly used applications, motivation for SMP usage practices, frequency in SMP usage, hours spent on SMPs, and what respondents would have used time for in the absence of a smartphone. The questions asked under vulnerability and societal cohesiveness included; what are the main types of SMP related vulnerabilities; can you remember a time where you or someone you know was using a smartphone which put your life at risk? Narrate the situation? Have you or the person used the smartphone for the same reason during a similar situation again? Can you remember a time where you or someone you know was using a mobile phone which put someone else's life at risk? What factors influence your response during an SMP related emergency situation? In what ways do you think SMP usage is affecting cultural identities? Questions on the positive impact of SMPs were also asked; can you remember a time where using a mobile phone (either by you or someone) saved your life? Narrate the situation? Can you remember a time where using a mobile phone (either by you or someone) saved someone's life?

These questions were used as conversation starters hence based on the responses provided, other probing questions were asked to ensure that detailed information needed for analyzing SMP usage patterns, human vulnerabilities, emergency responses and consequences on cultural identity and societal cohesiveness were obtained. Data analyses were done by providing illustrative quotes, categorizing emerging themes and determining the level of specificity and generality (Butterfield, Borgen, Amundson, \& Maglio, 2005). Results were categorized to determine the level of specificity and 
extent of generalization of the study findings in relation to the broader literature. The categorization of results was an iterative process until saturation of data was achieved (Strauss \& Corbin, 1998).

\section{The synergies between SMPs, human vulnerabilities and societal cohesiveness}

\subsection{Changing SMP usage pattern}

The findings reveal that on the average respondents in London and Accra have owned or used their SMPs for more than five years (5.75 years). The main uses of SMPs among respondents were social media applications and services such as WhatsApp, Facebook, and YouTube. Social media has replaced the conventional way of mobile communication. Fig. 2 captures participants SMP usage patterns. The uses of smartphones in both cities have changed from calling and texting to social media, reading news, recording videos and sending emails. This changing usage pattern is increasingly linked to advancements in mobile application technologies as smartphones now offer multiple connectivity and functionalities such as Wi-Fi, GPRS, instant messaging, voice messaging, video calling, and live streaming.

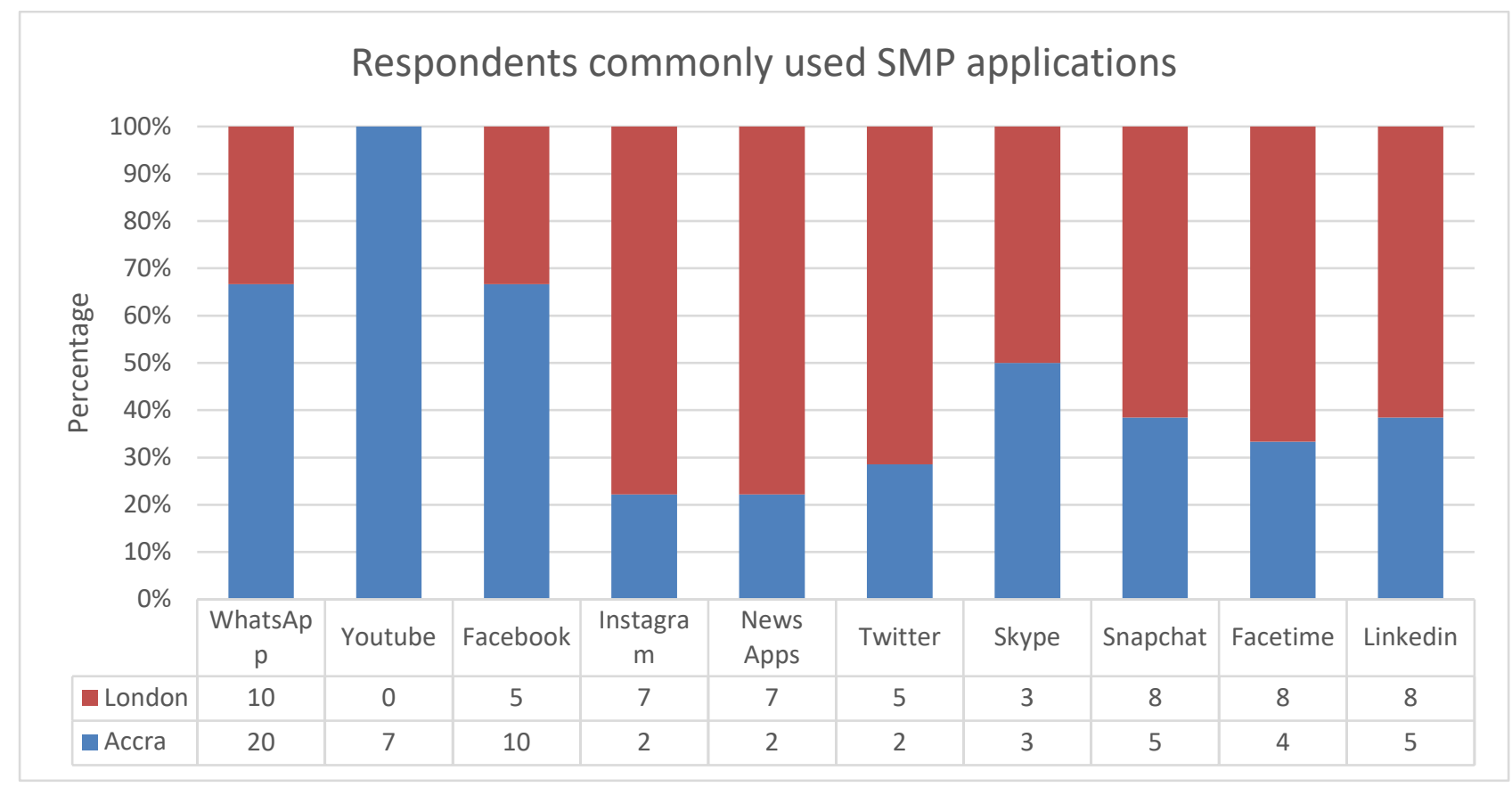

Figure 2: Respondents SMP usage patterns

Regarding these technological features, the motivation for smartphone use is triggered by accessibility, portability, user friendly interface, design, music and video player, navigation, etc (Oulasvirta, Rattenbury, Ma, \& Raita, 2012). The quotes below summarise the changing SMP usage patterns in Accra and London respectively.

Yes, my phone use has changed. In the past I had to buy newspapers for news but now it is all online and on social media so I use the phone more often. ... The phone also helps me to send images [photos] to customers so I use it as a marketing tool as well. (32-year-old male, Accra)

My phone usage pattern has changed because before there was no social media so little was 
being done with the phone but now, I am addicted to it. (25-year-old female, London)

The evolution in the social media world from messenger chatting to instant messaging, and recently to live streaming and snapchatting has both gender and age dimensions. Males tend to use social media for work or business and leisure whereas females often use it for family and friends and following online trends especially catering and fashion. This finding resonates with Tsitsika et al. (2009) who found that women use the internet mostly for social purposes and males do so for downloading programs, getting information, and for visiting pornographic sites. In addition, while the youth explore almost all the online application portals including video calls and live streams for entertainment and keeping groups active, those in their mid-thirties and above use applications like voice calling and text and voice messaging, particularly among the less educated population, and also follow online news updates. This finding illustrates how recent SMP technologies appeal to different social categories and age groups, complicating studies by Berg, Taylor, and Harper (2003) and Ozcan (2014) that the IT world is oriented towards the youth and designed for people with educational background.

The daily use duration of a smartphone is one of the most significant indicators of smartphone addiction. Using the addiction level of $3 \mathrm{~h}$ bar by Egger and Rauterberg (1996) and Bi et al. (2015), all but one respondent in Accra are addicted to SMPs while in London $70 \%$ of respondents are addicted. The prevalence of SMP usage among participants was $7 \mathrm{~h}$ a day among participants in London and around $5 \mathrm{~h}$ a day in Accra. Besides the fact that there is high smartphone penetration in the UK than Ghana, this finding could be explained by the high data cost in using social media in the latter, unlike the former where users subscribe to monthly packages and Wi-Fi connections are readily available. This finding corroborates Torrecillas (2007) who reported that $40 \%$ of adolescents and adults use smartphones for more than $4 \mathrm{~h}$ a day to make calls and send messages.

In both Accra and London respondents unanimously concurred that their addiction to smartphones hinders work productivity, potential skills development and physical connections with family and friends. In Accra the dominance of SMPs has reduced face-to-face contacts and visits to family members but instead, enabled them to connect virtually with family and friends -maintaining old and forging new ones, expanding business opportunities and catching up with trends, while in London, it has reduced reading time. Almost three quarter of respondents in London indicated that they would rather use time spent on SMP to read and acquire knowledge whereas in Accra this time would have been used for working and spending time with family and friends. This implies that SMP usage is potentially influencing productivity at the workplace and the collective tendency of Ghanaians (Markwei \& Appiah, 2016). These observations raise concerns regarding the vulnerability experiences of smartphone users.

\subsection{Human vulnerabilities and emergency response}

Attitudinal vulnerability is widespread among participants as 28 of them, representing $70 \%$, have experienced some form of smartphone related vulnerabilities or know victims of such vulnerabilities. All the vulnerabilities reported by participants were human-induced risks. These include victimisation, falsified relationships and broken hearts, stalking, privacy breach and loss of confidential data, injury, home emergency, road accidents and death. There is a similar vulnerability trend in both cities albeit with some peculiarities. SMPs influence human susceptibility to harm at three levels; individual, household and societal. While individual-type vulnerabilities dominate in London, Accra exhibited a mix of individual, household and societal-type vulnerabilities. Fig. 3 captures the levels of vulnerabilities in 
Accra and London.

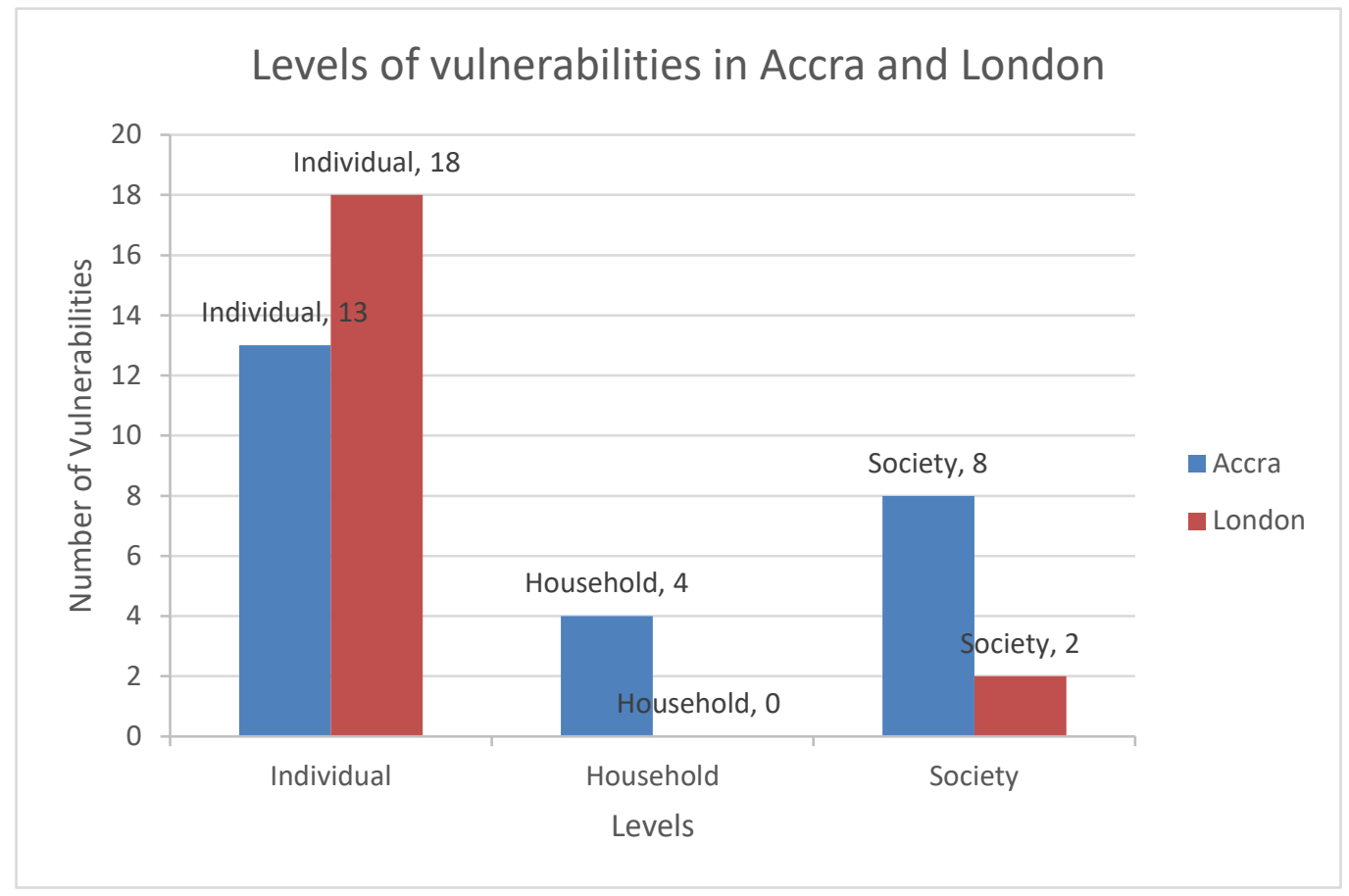

Figure 3: Levels of vulnerabilities in Accra and London

Individual level vulnerabilities are mainly influenced by personal attitudes (Walters \& Gilbert, 2000) such as addiction, distraction and fame seeking. The prevalent forms of individual vulnerabilities usually manifest in victimisation, falsified relationships, broken hearts, privacy breach, injury and home and road accidents. The most prevalent individual vulnerabilities are shown in Fig. 4.

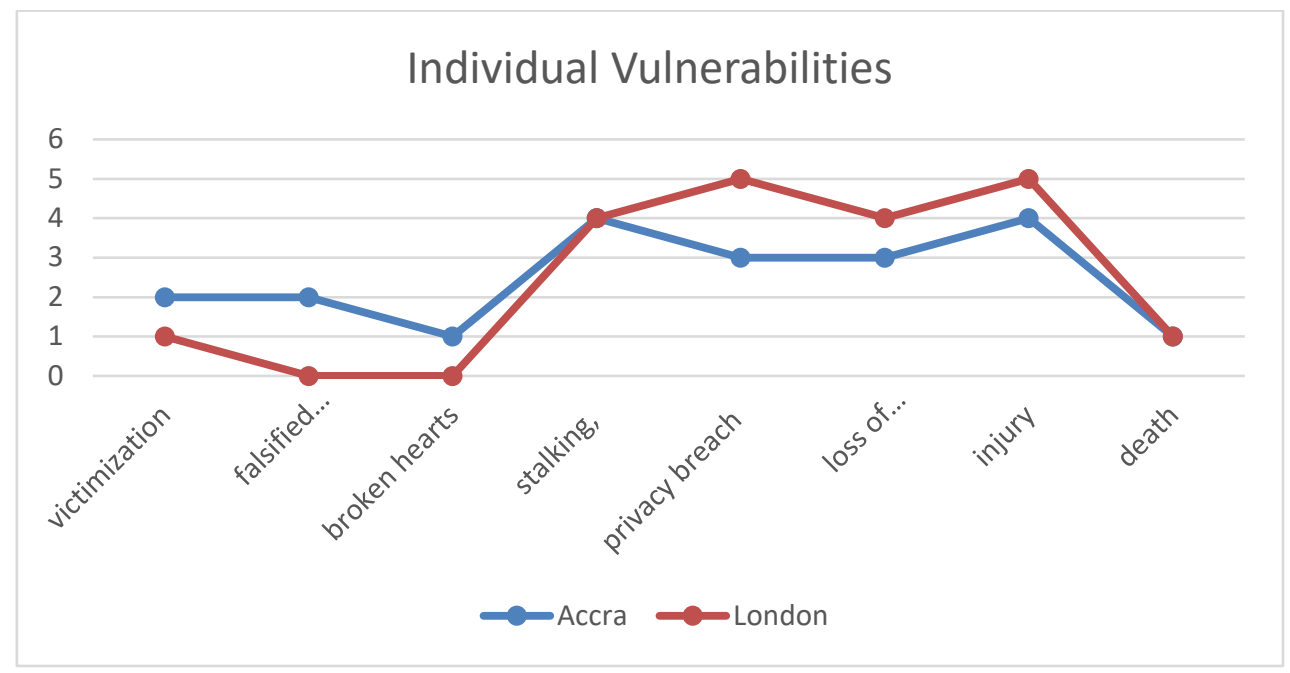

Figure 4: Prevalent individual vulnerabilities

Societal vulnerabilities manifest in home emergencies, road accidents, destruction of personal property and public infrastructure or facilities, and loss of genuine sense of care and people-centeredness which 
in effect are shaping cultural identities. It is not surprising that in both cities SMP related accidents have been on the ascendancy and noted as a major contributor to road fatalities (see GhanaWeb, 2013; Ingham, 2014; McCann, 2016). Individual and societal level vulnerabilities have direct and tangible bearing on household vulnerability. This includes collateral damages during home emergencies, financial costs for recovery and disruptions in daily activities schedule to respond to emergencies. The quote below summarises the multiple dimensions of individual vulnerabilities as discussed above.

You face them every day; my sister has become a victim of online scam and mobile-money fraud; my friend nearly burnt her kitchen and little baby because she was watching a food recipe online and cooking at the same time; my work colleagues have had road accidents and injuries, and lost phones and suitcases because they were walking and chatting. Myself I've broken blenders, plates and phone screen because I leave phone on my shoulder to instantly reply to posts when doing house chores. I've burnt my husband's clothes; and he even has pictures of me sleeping with my phone on my chest.

(27-year-old female, Accra)

It is worth mentioning that because smartphones contain confidential data like passcodes and bank details as well as private data such as chart histories, photos and videos once the phone is lost or stolen the users' data leak or become public. Moreover, through the varied (spyware) applications and functionalities, smartphones leak users' personal data which increases the vulnerability of phishing attacks (Wu, Miller, \& Garfinkel, 2006) whereby scammers and hackers send fake messages and emails in an attempt to gain access to confidential information including credit card details and passwords. On many occasions participants indicated that they share content on social networks without thinking about the consequences of such information flow. In London, SMP use has been reported to be associated with sexting scandals, online dating scams and privacy abuses. Mahmood (2013) draws our attention to how such issues have threatened people's marriages, careers and even landed others in jail. A quote below by a 30 -year-old male graduate illustrates this point.

I once mistakenly sent a drug prescription meant for a friend's fiancée to my class' group page. I've been tagged! People don't respect me as before. Some think I'm having extra marital affairs. ...A lady also wrongly posted on our page her private chats with the husband, I think they had a quarrel the previous night. Once you become a victim of wrong posts there's little you can do.

In Accra, one peculiar concern about the use of online social media is cyber fraud, colloquially known as sakawa. Cyber fraud includes using stolen credit cards to make online purchases, conducting online dating scams and luring contacts to participate in money transfers. One respondent intimated:

I search online for helpers. I tell them my plight; my parents are separated, I'm a street child and a beggar, with no one to pay my fees; to get their attention and request help from them later. But mine is not fraud. If they are convinced, they send the money. Some male clients in turn propose love to those who have concealed their identity and changed their sex.... Other people, but not me, cook stories and even support their requests with 'juju' [magic] (25-year-old male, Accra) 
Other vulnerability concerns, peculiar to the youth, pertain to exposure of underage users to pornography and immoral language, shirking of household chores in favor of social media use, and poor students' performance because of reduced study time, distraction from schoolwork, poor grammar and spelling and incorrect sentence construction due to the use of colloquial language on social media. That notwithstanding the use of social media also improves research activities and reading skills.

The causes of attitudinal vulnerabilities are strongly influenced by personal trait and disposition such as addiction, carelessness, over confidence to multi-task, curiosity and fame (as shown in Fig. 5). While our study corroborates the work of Bartlett et al. (2013) which cited addiction as a major cause of attitudinal vulnerability, it further contributes to the broader literature by introducing carelessness, over confidence to multi-task, curiosity and fame-seeking as important factors that influence SMP users' practices and attendant attitudinal vulnerabilities.

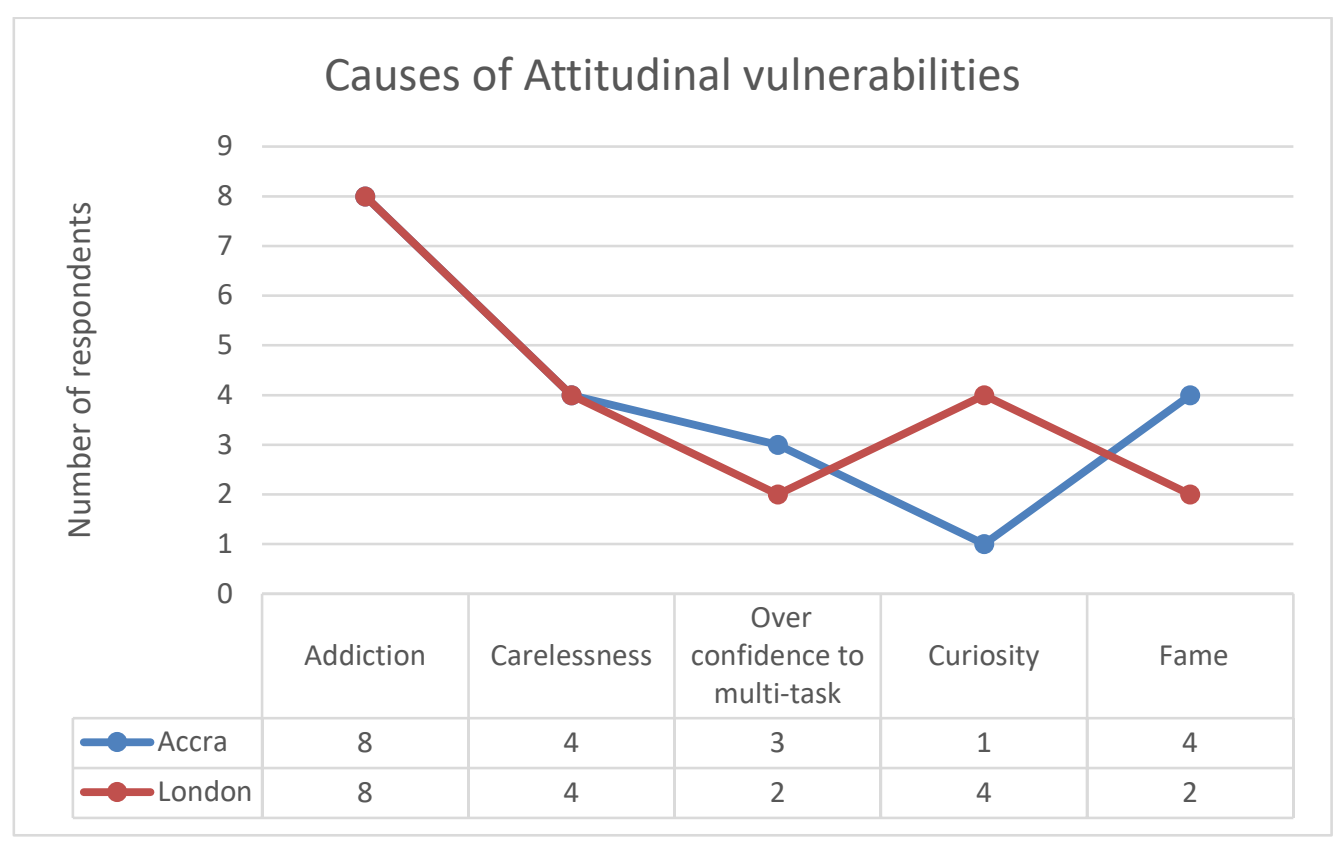

Figure 5: Causes of attitudinal vulnerability

The study also analyzed participants' response to attitudinal vulnerabilities. Contrary to the conceptual framework in Fig. 1, educational level and personal experiences did not have a strong influence on people's response to SMP related vulnerabilities. Nearly half of the respondents indicated that persons with higher education tend to have wider social networks and therefore risk becoming social media addicts. In addition, more than one-third of the participants who have had prior negative personal experiences of SMP related risks continue to engage in practices like multi-tasking which increases their susceptibility to harm. This finding suggests that human vulnerabilities increase even when there is awareness of disruptions and risks. Further, it shows how the social media world is perpetuating individualistic tendencies such that people project their personal traits (e.g. public fame) over the safety of third parties, as discussed in studies by Mahmood (2013) and Halevi et al. (2013).

Personal trait however was a major factor that influenced participants' response to vulnerabilities in 
London and Accra. The participants in London adopt self-discipline and restraint strategies such as controlling SMP addiction, locking data and phone and activating privacy settings. In the event of an emergency participants preferred to maintain their individuality and rather call emergency services. In the process, some take pictures and post online as eye witness evidence. The quote below buttresses the point.

The world system is changing. Nowadays everybody is extra careful about security. So when you see something unusual happening the best thing to do is you call emergency and maybe take pictures to help investigations (29-year-old female, London)

In Accra, normally people would provide 'first aid' during emergency situations before reporting or calling emergency services. This is probably because of the low public confidence in emergency services and contacts and rapid response. The 'first aid' process involves people taking pictures and videos to share with their social media networks before providing direct helping hands such as taking a victim to hospital, shouting or signalling a pedestrian to draw attention to impending danger, intervening to calm the situation and offering a phone to call victim's relatives. The quotes below throw more light on this point.

Last month I had to rush my madam's baby to the hospital because she poured a bowl of boiling oil on herself; because I left her in the kitchen to answer a call. I was barefooted and half naked; just wearing brassiere and an underwear. Bystanders were videoing me but I didn't even realize what was happening. (23-year-old female, Accra)

The sharp cameras and live chat apps tell users what to do with SMPs. So if you see an accident or an unusual event you have to take pictures so that people will believe you in case you post the event to them. The police even ask for evidence. (36-year-old male, Accra)

Besides these vulnerabilities SMPs are also associated with some positive aspects. During emergencies SMPs are used to trace family contacts and call emergency services, track lost devices and properties, take photos to provide evidence and facilitate investigation and raise media awareness. On many occasions, respondents recounted how they wasted time and money to attend cancelled appointments or meetings because they failed to check alerts on social media. Some narrated how relatives were robbed or sickness worsened because they failed to instantly check WhatsApp alerts requesting them to call emergency services. For city dwellers, such tendencies occupy two ends of a spectrum as they present rewards and risks: on the one instance staying active on social media can save emergency situations while on the other hand becoming too addicted can cost lives. These perspectives raise concerns for people's genuine sense of care and people-centeredness which have implications for societal cohesiveness and cultural identities.

\subsection{Societal cohesiveness and cultural identity}

The study corroborates LeFebvre and Franke (2013) as the findings confirm that the Ghanaian society values collectivism more highly than the United Kingdom, albeit Ghanaians response to vulnerabilities exhibits strong inclinations towards individualism. Here, the term 'virtual collectivism' is adopted to show 
how SMP usage is making people more remotely connected but physically distant with a decline in genuine human interactions. In London, participants respond to vulnerabilities in a more individualistic manner at the household level. A respondent recounted her experience of sharing a vehicle to work with her colleague who always texted while driving. Instead of showing concern and cautioning him, she was self-centered and stopped car sharing. At the societal level, some tendencies of virtual collectivism were observed as almost all respondents indicated they used their SMPs to call emergency services to help situations. However, in Accra, participants indicated that the addiction and crave for fame on social media is eroding Ghanaian collectivism and perpetuating individualistic tendencies. Although at the individual and household levels there is virtual collectivism - people are more connected to wider social networks and can stay in touch with long distant relationships, the impact at the societal level is physical distance - people are losing their genuine sense of belongingness and responsibility of care for one another. The quotes below emphasise the point.

Mobile phones are taking away the best part of our lives, and it makes us think we are closer but we are actually very apart. It makes us compare ourselves with others and bring unnecessary competitions because people put the best parts of their lives there and make those who haven't been successful feel down. I think social media should be scrapped.

(22-year-old male, London)

We think smartphone is making us connected but its eroding our moral and cultural values as Ghanaians. Look at the recent Major Mahama's case; through social media we all saw the gruesome act: but the pictures and videos were nude and heart breaking. No one helped; they watched him lynched and rather took pictures. This is not Ghanaian.

(25-year-old female, Accra)

These comments highlight how the exposure to smartphone technologies underpinned by the insatiable appetite for online social media is altering both individuals' personality, rights and lifestyles; as well as cultural identity and societal cohesiveness. Smartphones are contributing to cultural transitions and triggering changes in the degree of collectivism and individualism in modern societies. Self-discipline, attitudinal changes and proper enforcement of laws that ban the use of mobile phones while driving including issuing points to drivers, and penalizing those who put their lives and others at risk were proffered as key strategies to reducing SMP related vulnerabilities and promoting people-oriented protection strategies.

\section{Revisiting SMP usage patterns, human vulnerabilities, cultural identity and ICT policy}

To contextualize our conceptual framing the framework in Fig. 1 was revisited to reflect the factors that influence smartphone usage patterns, attitudinal vulnerabilities and participants' emergency responses. The major changes observed in the revised framework illustrated in Fig. 6 are the components of socioeconomic factors which are occasioning a cultural transition. Under socio-economic factors the findings reveal that SMP usage behaviour and vulnerabilities are strongly influenced by personal traits and disposition such as addiction, carelessness, over confidence to multi-task, curiosity and fame seeking rather than educational level and personal experiences. This suggests that human vulnerabilities increase even when there is awareness of disruptions and users prior experience. The study advances 
the importance of personality traits to demographic and socio-economic factors in our understanding of smartphone users' practices and perceived risks (see Alsaleh et al., 2017). It also adds weight to the growing scholarship on smartphones and online social media vulnerabilities (Cha \& Se0, 2018). Based on the foregoing discussions, Fig. 6 stitches together a developed framing of SMP usage patterns, human vulnerabilities, cultural identity and ICT policy. The modifications to the initial framework (Fig. 1) have been indicated in italics.

Responses to these vulnerabilities are leading to a new type of social exclusion which is putting societies on a path of cultural transition, and altering the degree of collectivism and individualism. Specifically, the study corroborates Halevi et al. (2013) and Kulkarni and Bojewar (2015) who found a direct link between cyber security and privacy related behaviour and personality traits in the context of smartphone vulnerabilities. Our present study has emphasized the importance of personal traits and disposition in understanding SMP usage patterns, human vulnerabilities and emergency response. Further, it has under- scored the centrality of personality traits in any future ICT policy especially if the urban SDG of building inclusive, safe, resilient and smart sustainable cities is to be achieved.

In effect, in addition to cities experiencing changes in their political, economic, religious and social systems, there is a rapid but subtle revolution occurring in people's social relationships, under the aegis of smartphone technologies and social medial platforms that may require redefinition of in-groups and out-groups and assigning different meanings and significance to personal traits - the concepts of self, identity and fame (Amankwaa, 2017; Parker et al., 2009). These changes in disposition require shifts in attitudes, values and lifestyles, as well as plans and strategies towards addressing future risks and vulnerabilities in cities. These observations reveal how cities can best be envisaged as a mobile networked whole consisting of connected and compartmentalised systems, risks and human agency (Skelton \& Gough, 2013) and may have implications for how we examine cities and their surrounding peripheries and rural areas.

While government policies and punitive measures such as arresting and issuing points to drivers who use SMP while driving (DVLA, 2017) are encouraging in deterring addicted users and saving lives, future IT related policies should be broadly conceptualized to encompass the everyday human induced vulnerabilities. For instance, national campaign programs and education on online privacy, fame syndrome awareness, and emergency reporting helplines/platforms, data packages and bounty should be championed by the telecommunication industry and their relevant stakeholders. This will promote attitudinal changes among smartphone users and motivate people to act as 'Good Samaritans' in the event of emergency situations. Citizens should be encouraged to report SMP related emergencies rather than handling them personally to help build a national database system. The essential services in Ghana, particularly the police, security and health services, should be supported with the logistics necessary to detect, isolate and provide detailed records of SMP related emergencies. This will create a database of everyday vulnerabilities associated with smartphones thereby raising awareness, and presenting the on-the-ground realities necessary to inform any cutting-edge and evidence-based ICT policy.

\section{Concluding remarks}


As world cities become less isolated, change is undoubtedly expected to occur. The high ICT adoption rate coupled with the attendant addiction to smartphone technologies is fast-tracking this dynamism and melding cultures. While this emerging technology, particularly social media practices, privacy threats and security risks have been amply documented (Buglass et al., 2016; Mahmood, 2013), the same academic attention has not been given to the synergies between smartphones and everyday human vulnerabilities (Kulkarni \& Bojewar, 2015). This paper has shown how smartphones offer multiple connectivity, applications, and functionalities which help foster new and reconnect old friendships, build distant and virtual networks, and provide real time information that can save emergency situations. There is also a strong association between exposure to SMPs and increased attitudinal vulnerabilities. Importantly, attitudinal vulnerabilities are not only influenced by educational level and addiction as previous studies articulate (Bartlett et al., 2013; King et al., 2013), but also carelessness, over confidence to multi-task, curiosity and fame- seeking are important personal trait and lifestyle factors that influence smartphones users' practices and vulnerabilities. This has implications beyond this study for how we should theorize, conceptualize, analyze and manage vulnerabilities in cities.

The paper has revealed how cities today do not wholly epitomize Hofstede's $(1980,1991)$ labelling of collectivism among least developed countries and individualism among advanced countries (see Fiske, 2002). This study challenges Accra's collectivism tendency and confirms London's individualism inclination though some tendencies of virtual collectivism were observed. By comparing participants' smartphone usage patterns and their motives for adopting or ignoring certain social media practices, the study emphasizes how the concept of attitudinal vulnerability and associated emergency responses extends our understanding of Hofstede's cultural dimension theory. This paper contributes to broader debates on how technology shapes vulnerabilities and cultural identities by providing new empirical data on how smartphones and social media networks are altering the traditional notions of Westerncentric individualism and African-centric collectivism. This dynamism should be considered in policy making especially under the 'economy' and 'people' domains of smart cities.

Overall, by examining smartphone usage patterns related to utilizing many smartphone applications, we confirm, extend and refine findings of prior studies (Battarra et al., 2016; Buglass et al., 2016; Cha \& Seo, 2018; Mahmood, 2013) by providing evidence that users' SMP behaviour, vulnerability experience and emergency response are influenced by multiple factors, mainly personal traits and lifestyle and not merely education or personal experience. Given the widespread forms of attitudinal vulnerabilities among smartphone users in both cities, the study concludes that moving towards a people-centered agenda that focuses on personality traits and issues of attitudes, values and lifestyles as a basis for future action is an important starting point for minimizing human-induced vulnerabilities and realizing safe and smart cities. This study thus adds weight to scholarship arguing for local contextualization and a paradigm shift in how cities are planned and managed in terms of addressing future risks and vulnerabilities (Aina, 2017; Alsaleh et al., 2017; Batty, 2013; Neirotti et al., 2014). 


\section{References}

Adger, W. N. (2006). Vulnerability. Global Environmental Change, 16, 268-281.

Aina, Y. A. (2017). Achieving smart sustainable cities with GeolCT support: The Saudi evolving smart cities. Cities, 71, 49-58.

Akamai (2016). Q1 2016 State of the internet connectivity report. Akamai, 9(1), 1-64.

Alsaleh, M., Alomar, N., \& Alarifi, A. (2017). Smartphone users: Understanding how security mechanisms are perceived and new persuasive methods. PLoS One, 12(3),

Amankwaa, E. F. (2017). Water and Electricity Access for Home-based Enterprises and Poverty Reduction in the Greater Accra Metropolitan Area (GAMA). Ghana: University of Ghana (Unpublished PhD thesis, 2017).

Barclays (2017). Way to pay. Retrieved from http://www.barclays.co.uk/ways-to-pay.

Bartlett, R., Brown, L., Shattell, M., Wright, T., \& Lewallen, L. (2013). Harm reduction:

Compassionate care of persons with addictions. Medsurg Nursing, 22(6), 349.

Battarra, R., Gargiulo, C., Pappalardo, G., Boiano, D. A., \& Oliva, J. S. (2016). Planning in the era of Information and Communication Technologies. Discussing the "label: Smart" in the South-European cities with environmental and socio-economic challenges. Cities, 59, 17.

Batty, M. (2013). Big data, smart cities and city planning. Dialogues in Human Geography, 3(3), 274-279.

Berg, S., Taylor, A. S., \& Harper, R. (2003, April). Mobile phones for the next generation: device designs for teenagers. Proceedings of the SIGCHI Conference on Human Factors in Computing Systems (pp. 433-440). ACM.

Bi, Y., Yuan, K., Feng, D., Xing, L., Li, Y., Wang, H., ... Tian, J. (2015). Disrupted interhemispheric functional and structural coupling in Internet addiction adolescents. Psychiatry Research: Neuroimaging, 234(2), 157-163.

Birkmann, J., Cardona, O. D., Carreño, M. L., Barbat, A. H., Pelling, M., Schneiderbauer, S., ... Welle, T. (2013). Framing vulnerability, risk and societal responses: The MOVE framework. Natural Hazards, 67(2), 193-211.

Buglass, S. L., Binder, J. F., Betts, L. R., \& Underwood, J. D. M. (2016). When 'friends' collide: Social heterogeneity and user vulnerability on social network sites. Computers in Human Behavior, 54, 62-72. 
Butterfield, L. D., Borgen, W. A., Amundson, N. E., \& Maglio, A. S. T. (2005). Fifty years of the critical incident technique: 1954-2004 and beyond. Qualitative Research, 5(4), 475-497.

Cannon, T., Twigg, J., \& Rowell, J. (2003). Social vulnerability, sustainable livelihoods and disasters. Londres: DFID.

Cha, S. S., \& Seo, B. K. (2018). Smartphone use and smartphone addiction in middle school students in Korea: Prevalence, social networking service, and game use. Health Psychology Open, 1-15.

Chan, M. (2015). Mobile phones and the good life: Examining the relationships among mobile use, social capital and subjective well-being. New Media \& Society, 17(1), 96-113.

DVLA (2017). Penalty points. Retrieved from https://www.gov.uk/penalty-pointsendorsements/new-drivers.

Egger, O., \& Rauterberg, M. (1996). Internet behavior and addiction. Zurich: Swiss Federal Institute of Technology (Semester thesis, 1996).

Falaki, H., Mahajan, R., \& Kandula, S. (2010). Diversity in smartphone usage. Proceedings of the 8th International Conference on Mobile Systems, Applications, and Services (MobiSys) (pp. 179-194).

Fellows, R. F., \& Liu, A. M. (2008). Research methods for construction (3rd ed.). Chichester: Blackwell Publishing.

Fiske, A. P. (2002). Using individualism and collectivism to compare cultures-A critique of the validity and measurement of the constructs: Comment on Oyserman et al. (2002).

Fuchs, C. (2017). Social media: A critical introduction. Sage.

Gallopín, G. C. (2006). Linkages between vulnerability, resilience, and adaptive capacity. 16, 293-303. http://dx.doi.org/10.1016/j.gloenvcha.2006.02.004.

GhanaWeb (2013). The hidden cause of road accidents and deaths. Retrieved from https://www.ghanaweb.com/GhanaHomePage/NewsArchive/The-hidden-cause-of- roadaccidents-and-deaths-282863.

Greenwood, D. N. (2013). Fame, Facebook, and Twitter: How attitudes about fame predict frequency and nature of social media use. Psychology of Popular Media Culture, 2(4), 222-236.

GSS (Ghana Statistical Service) (2012). 2010 population and housing census: Summary re- port of final results. Accra: GSS.

Guardian (2014). London welcomes largest number of visitors since 1961. Retrieved from https://www.theguardian.com/news/datablog/2014/may/09/2013-highest- 
number-london-visitors-since-1961-tourists.

Halevi, T., Lewis, J., \& Memon, N. (2013). A pilot study of cyber security and privacy related behavior and personality traits. WWW 2013 Companion, May 13-17, 2013, Rio de Janeiro, Brazil ACM 978-1-4503-2038-2/13/05.

Hampshire, K., Porter, G., Owusu, S. A., Mariwah, S., Abane, A., Robson, E., ... Milner, J. (2015). Informal m-health: How are young people using mobile phones to bridge healthcare gaps in Sub-Saharan Africa? Social Science \& Medicine, 142, 90-99.

Heimbach, I., Schiller, B., Strufe, T., \& Hinz, O. (2015). Content virality on online social networks: Empirical evidence from Twitter, Facebook, and Google+ on German news websites. Proceedings of the 26th ACM Conference on Hypertext \& Social Media (pp. 39-47). ACM.

HMRS (2017). Proposed benefit and pension rates 2017 to 2018. Retrieved from https:// www.gov.uk/government/publications/proposed-benefit-and-pension-rates-2017-to- 2018.

Hofstede, G. (1980). Culture's consequences: International differences in work-related values. Beverly Hills, CA: Sage.

Hofstede, G. (1991). Cultures and organizations: Software of the mind. London: McGraw- Hill.

Ingham, J. (2014). Mobile phones are biggest cause of road fatalities. Retrieved from http://www.express.co.uk/news/uk/490393/Mobile-phone-use-the-biggest-causeof-road-fatalities, Accessed date: 6 September 2017.

Internet World Statistics (2017). Africa 2017 population and Internet users statistics. Retrieved from http://www.internetworldstats.com/stats1.htm.

ITU (2013). ICT facts and figures 2013. Retrieved from http://www.itu.int/en/ITU-D/ Statistics/Pages/stat/default.aspx.

King, A. L. S., Valença, A. M., Silva, A. C. O., Baczynski, T., Carvalho, M. R., \& Nardi, A. E. (2013). Nomophobia: Dependency on virtual environments or social phobia? Computers in Human Behavior, 29(1), 140-144.

Kulkarni, S. P., \& Bojewar, S. (2015). Vulnerabilities of smartphones. International Research Journal of Engineering and Technology, 2(9), 2422-2426.

LeFebvre, R., \& Franke, V. (2013). Culture matters: Individualism vs. collectivism in conflict decision-making. Societies, 3(1), 128-146.

Mahmood, S. (2013). Online social networks: Privacy threats and defenses. In R. Chbeir, \& B. Al Bouna (Eds.). Lecture notes in social networks. Springer-Verlag 
Wienhttp://dx. doi.org/10.1007/978-3-7091-0894-9 (2, 2013).

Markwei, E. D., \& Appiah, D. (2016). The impact of social media on Ghanaian youth: A case study of the Nima and Maamobi communities in Accra, Ghana. The Journal of Research on Libraries and Young Adults, 7(2), 1-26.

Marshall, M. N. (1996). Sampling for qualitative research. Family Practice, 13(6), 522-526.

McCann, K. (2016). Drivers could be blocked from using mobile phones at the wheel in a bid to curb road deaths. Telegraph Media Group Limited. 2017. Retrieved from http://www.telegraph.co.uk/news/2016/12/19/drivers-could-blocked-using- mobilephones-wheel-bid-curb-road/, Accessed date: 6 September 2017.

Morris, M. H., Davis, D. L., \& Allene, J. W. (1994). Fostering corporate entrepreneurship: Cross-cultural comparisons of the importance of individualism versus collectivism. Journal of International Business Studies, 25(1), 65-89.

Neirotti, P., De Marco, A., Cagliano, A. C., Mangano, G., \& Scorrano, F. (2014). Current trends in Smart City initiatives: Some stylised facts. Cities, 38, 25-36.

OCIA (Office of Cyber and Infrastructure Analysis) (2015). The future of Smart Cities: Cyber-physical infrastructure risk. National Protection and Programs Directorate Office of Cyber and Infrastructure Analysis. U.S. Department of Homeland Security.

ONS (Office of National Statistics) (2016). Subnational population projections for England. Retrieved from https://www.ons.gov.uk/peoplepopulationandcommunity/ populationandmigration/populationprojections/bulletins/ subnationalpopulationprojectionsforengland/2014basedprojections.

ONS (Office of National Statistics) (2017). Digital Technology enterprises in districts of England. Retrieved from https://www.ons.gov.uk/businessindustryandtrade/ business/activitysizeandlocation/adhocs/ 005504 digitaltechnologyenterprisesindistrictsoftheeastofengland20092014and2015.

Oulasvirta, A., Rattenbury, T., Ma, L., \& Raita, E. (2012). Habits make smartphone use more pervasive. Personal and Ubiquitous Computing, 161(1), 105-114.

Ozcan, A. (2014). Mobile phones democratize and cultivate next-generation imaging, diagnostics and measurement tools. Lab on a Chip, 14(17), 3187-3194.

Pain, R., Grundy, S., Gill, S., Towner, E., Sparks, G., \& Hughes, K. (2005). 'So long as I take my mobile': Mobile phones, urban life and geographies of young people's safety. International Journal of Urban and Regional Research, 29(4), 814-830.

Parker, S. R., Haytko, D. L., \& Hermans, C. M. (2009). Individualism and collectivism: Reconsidering old assumptions. Journal of International Business Research, 8(1). Porter, G., Hampshire, K., Abane, A., Munthali, A., Robson, E., Bango, A., ... Milner, J. 
(2015). Intergenerational relations and the power of the cell phone: Perspectives on young people's phone usage in sub-Saharan Africa. Geoforum, 64, 37-46.

Ruths, D., \& Pfeffer, J. (2014). Social media for large studies of behavior. Science, 346(6213), 1063-1064.

Saunders, M., Lewis, P., \& Thornhill, A. (2012). Research methods for business students (6th ed.). Harlow: Pearson.

Schanze, J. (2006). Flood risk management-A basic framework. Flood risk management: Hazards, vulnerability and mitigation measures (pp. 1-20). Dordrecht: Springer.

Skelton, T., \& Gough, K. V. (2013). Young people's im/mobile urban geographies: Introduction. Urban Studies, 50, 455-466.

Smit, B., \& Wandel, J. (2006). Adaptation, adaptive capacity and vulnerability. Global Environmental Change, 16, 282-292.

Statista (2017). Number of smartphone users worldwide from 2014 to 2020. Retrieved from https://www.statista.com/statistics/330695/number-of-smartphone-users- worldwide/.

Strauss, A., \& Corbin, J. (1998). Basics of qualitative research techniques. Sage publications. TFL (2017). Apple Pay. Retrieved from https://tfl.gov.uk/fares-and-

payments/contactless/other-methods-of-contactless-payment/apple-pay.

Torrecillas, L. (2007). Mobile phone addiction in teenagers may cause severe psychological disorder. Medical Studies, 14, 11-13.

Triandis, H. C. (1995). Individualism and collectivism. Boulder, CO: Westview Press.

Triandis, H. C. (2004). The many dimensions of culture. Academy of Management Executive, 18(1), 88-93.

Tsitsika, A., Critselis, E., Kormas, G., Konstantoulaki, E., Constantopoulos, A., \& Kafetzis, D. (2009). Adolescent pornographic internet site use: A multivariate regression analysis of the predictive factors of use and psychosocial implications. CyberPsychology and Behavior, 12, 545-550.

Turkle, S. (2011). Alone together. New York: Basic Books.

Walters, G. D., \& Gilbert, A. A. (2000). Defining addiction: Contrasting views of clients and experts. Addiction Research, 8(3), 211-220.

Wu, M., Miller, R. C., \& Garfinkel, S. L. (2006, April). Do security toolbars actually prevent phishing attacks? Proceedings of the SIGCHI Conference on Human Factors in Computing Systems (pp. 601-610). ACM. 